\title{
Ex vivo evaluation of three instrumentation techniques on $E$. faecalis biofilm within oval shaped root canals
}

\section{Vitor Cesar NAKAMURA(a) George Taccio de Miranda CANDEIRO(a) \\ Silvana $\mathrm{CAI}^{(\mathrm{b})}$ \\ Giulio GAVINI(a)}

(a) Universidade de São Paulo - USP, Dental School, Department of Dentistry, São Paulo, SP, Brazil.

(b) Universidade de São Paulo - USP, Institute of Biomedical Sciences, Department of Microbiology, São Paulo, SP, Brazil.

Declaration of Interests: The authors certify that they have no commercial or associative interest that represents a conflict of interest in connection with the manuscript.

Corresponding Author:

Giulio Gavini

E-mail: ggavini@usp.br

DOI: 10.1590/1807-3107BOR-2015.vol29.0027

Submitted: Jul 21, 2014

Accepted for publication: Oct 15, 2014

Last revision: Dec 09, 2014

\begin{abstract}
The objective of the present study was to assess the effectiveness of reciprocating instrumentation in disinfecting oval-shaped root canals infected with Enterococcus faecalis. Forty-five human lower premolars were infected with a culture of E. faecalis (ATCC 29212) for 28 days. Five other teeth that were neither contaminated nor instrumented were used as controls. The 45 specimens were divided into three experimental groups $(n=15)$ based on the root canal preparation technique used: manual (K-type, Dentsply Maillefer, Ballaigues, Switzerland); rotary (MTwo, VDW GmbH, Munich, Germany); and reciprocating (Reciproc R50, VDW $\mathrm{GmbH}$, Munich, Germany) instruments. During chemomechanical preparation, $21 \mathrm{~mL}$ of $2.5 \% \mathrm{NaOCl}$ was used as the irrigating solution. Microbiological sampling was performed before (S1) and immediately after (S2) the chemomechanical preparation using sterilized paper points. Specimens were then cleaved, and $0.02 \mathrm{~g}$ of dentine chips was collected from the root thirds to verify the presence of microorganisms in dentinal tubules. All three preparation techniques reduced the number of microorganisms in the root canal lumen and dentine chips from the root thirds, but no significant differences were observed between the three groups $(p>0.05)$. Reciprocating instrumentation with Reciproc R50 was effective in reducing the number of microorganisms within the root canal system. Although this technique involves the use of only one file to perform the root canal therapy, it is as effective as conventional rotary instrumentation in reducing the E. faecalis biofilm from the root canal system. However, further clinical investigations are warranted in order to ratify these results.
\end{abstract}

Keywords: Endodontics; Root Canal Preparation; Root Canal Therapy; Dental Instruments.

\section{Introduction}

Bacteria and their byproducts are the primary etiologic agents of pulp and periapical diseases. During root canal treatment, most of these microorganisms are eliminated during chemo-mechanical preparation. ${ }^{1}$ However, several authors have shown that oval shaped root canals can hinder proper debridement and disinfection of the dentinal walls., . $3,4,5,6^{-1}$ The complex anatomy of this type of root canal system favors the persistence of bacteria cells ${ }^{2}$ as several portions of the root canal walls remain untouched even after root canal preparation. These untouched 
areas of the infected root canal may retain residual bacterial biofilm, leading to persistent periapical disease and poor treatment outcomes.

The organization of microorganisms in biofilms increases the resistance of these pathogens to endodontic procedures, hindering root canal disinfection. Enterococcus faecalis has a high prevalence in cases of persistent apical periodontitis and has been widely studied in endodontics. ${ }^{7}$ This microorganism can form biofilms even in environments where nutrients are scarce. ${ }^{8}$ E. faecalis can penetrate deeply into the dentin, rendering complete elimination difficult ${ }^{9}$ and can survive in high $\mathrm{pH}$ environments without interacting with other microorganisms. ${ }^{7}$

To overcome the above-mentioned anatomical and microbial challenges, the disinfection abilities of different substances and procedures have been studied, especially through ex vivo experiments involving E. faecalis biofilm models. ${ }^{4,6,10,11,12,13,14}$ In addition, various materials and techniques have been introduced to improve the shaping and disinfection of the root canal system. Since 2008, two innovations including a new type of nickel-titanium (NiTi) alloy and an instrument offering reciprocating movement ${ }^{15,16,17}$ have been studied. Developed through special thermal treatment, ${ }^{18,19}$ the M-Wire NiTi alloy shows greater flexibility and resistance to fracture than conventional NiTi alloys, permitting its safe use throughout all stages of endodontic instrumentation. ${ }^{15}$

The reciprocating instrument rotates counterclockwise and clockwise, alternating the cut rotation at $120^{\circ}$. This approach has been shown to apply less stress to the instrument, increase the resistance of the file to flexural fatigue and expand the lifespan of the instrument. ${ }^{17}$ Unlike rotary instrumentation, which uses a sequence of several instruments, the reciprocating movement concept employs only one instrument throughout the entire process of root canal preparation. Several modifications in the kinematics and number of instruments required to perform endodontic treatment led to a substantial decrease in root canal preparation time. However, this also resulted in a decrease in contact time between the irrigant and the root canal walls. Therefore, the effects of reciprocating instruments on microbial contents of the root canal system need to be evaluated.
The aim of the present study was to evaluate the effectiveness of Reciproc R50 files in disinfecting oval root canals infected with E. faecalis, ex vivo. The null hypothesis was that there would be no differences between reciprocating, rotary, and manual instrumentation in reducing the bacterial count of infected oval-shaped root canals.

\section{Methodology}

All teeth used in the present study were donated by the permanent teeth bank, and the study was approved by the Research Ethics Committee of the Dental School at the Universidade de São Paulo - USP (0035.0.132.00-11).

Fifty human mandibular premolars with straight roots, single canals and no previous endodontic treatment, internal resorption, calcifications, root dilacerations or other anatomical or pathological alterations, were selected. The teeth were selected on the basis of periapical radiographs taken in the bucco-lingual and mesio-distal directions. The ratios between the bucco-lingual and mesio-distal dimensions of the root canals were greater than 2.5:1, when measured $5 \mathrm{~mm}$ from the root apex. ${ }^{6}$

To maintain hydration, the specimens were stored in saline for at least 7 days. Dental crowns were sectioned with diamond discs (KG Sorensen, São Paulo, Brazil) to standardize the root length to $15 \mathrm{~mm}$. Root canals were enlarged using K-files (size 30; Dentsply Maillefer, Ballaigues, Switzerland) and saline, until the instrument tip reached the apical foramen. Transversal sulci, $0.5 \mathrm{~mm}$ in depth, were made at 5.0 and $10.0 \mathrm{~mm}$ away from the apex of each tooth using a 0.2 -mm-thick diamond disc, in order to cleave the specimens after root canal preparation. The specimens were immersed in an ultrasonic bath containing 17\% EDTA-T (Fórmula e Ação Laboratórios de Manipulação, São Paulo, Brazil) for 3 minutes, followed by immersion in $5.25 \% \mathrm{NaOCl}$ (Fórmula e Ação Laboratórios de Manipulação) for 5 minutes and finally in distilled water for 3 minutes. After drying, the roots were covered with two layers of nail polish ensuring that the apical foramen was adequately sealed. After 24 hours, the teeth were individually inserted into 1.5-mL polypropylene tubes (CRAL - 
Artigos para Laboratório Ltda., São Paulo, Brazil) and autoclaved at $121^{\circ} \mathrm{C}$ for 20 minutes.

Inoculum was prepared by adding $50 \mu \mathrm{L}$ of $E$. faecalis strain (ATCC 29212) to $50 \mathrm{~mL}$ of Tryptic Soy Broth (TSB, Difco Labs, Sparks, USA) under aerobic conditions at $37^{\circ} \mathrm{C}$ for 24 hours. The inoculum density was calibrated until its turbidity reached level 4 on the McFarland scale, corresponding to $1.2 \times 10^{9}$ colonyforming units per milliliter $(\mathrm{CFU} / \mathrm{mL})$. Root canals were inoculated and kept under aerobic conditions at $37^{\circ} \mathrm{C}$ for 28 days. TSB was renewed every two days to ensure the maintenance of the culture viability. After the incubation period, the root canals were filled with sterile peptone water. Preoperative samples (S1) were collected using three size 20 sterile paper cones (Dentsply Maillefer). Each paper cone was placed at the working length for 1 minute and then stored in polypropylene tubes containing $1 \mathrm{~mL}$ of sterile peptone water. A 10-fold serial dilution was performed. To confirm the contamination of the specimens, $50-\mu \mathrm{L}$ aliquots were plated on Triptic Soy Agar (TSA, Difco Labs). After 48 hours of incubation at $37^{\circ} \mathrm{C}$, microbial growth was observed and the absence of contamination with other microbes was confirmed by Gram staining and colony morphology observations. Four teeth were fixed in 10\% buffered formalin and processed for scanning electron microscopic (SEM) analysis to confirm bacterial colonization and biofilm formation, as described previously by Siqueira Jr et al. ${ }^{4}$ The control group used to demonstrate specimen sterility consisted of five teeth that were neither contaminated nor instrumented.

Forty-five specimens were randomly divided into three groups $(n=15)$, according to the chemomechanical preparation technique applied. Specimens were subjected to manual instrumentation (group 1) using K-files (Dentsply Maillefer, Ballaigues, Switzerland), rotary instrumentation (group 2) using MTwo files (VDW GmbH, Munich, Germany), or reciprocating instrumentation (group 3) using Reciproc R50 files (VDW GmbH, Munich, Germany). The working length was $14 \mathrm{~mm}$ in all specimens. Prior to root canal preparation, all instruments used in groups 1 and 2 were autoclaved at $121^{\circ} \mathrm{C}$ for 20 minutes. The Reciproc R50 files, in group 3, were previously sterilized by the manufacturer.
In group 1 , the cervical third of the root canal was enlarged with size 2 and size 3 Gates-Glidden drills. Medium and apical preparations were performed with K-files up to size 50, starting with size 30 files. The instruments were inserted to the working length and then pressed against the root canal walls using filing motions with amplitude of approximately $2 \mathrm{~mm}$.

In groups 2 and 3 , instrumentation was performed with an electric motor (VDW Silver Reciproc, VDW $\mathrm{GmbH}$ ), which was adjusted for continuous rotation at $300 \mathrm{rpm}$ (group 2) or reciprocating movement (group 3). MTwo files were used in the sequence of $15.05,20.06,25.06,30.05,35.04,40.04$, and 50.04 to working length, in group 2, while in group 3 , the root canals were instrumented in a sequence of three steps, each consisting of three pecking movements. After each step, the root canal was irrigated with $2.5 \% \mathrm{NaOCl}$, and the file was cleaned. The working length in group 3 was only reached in the final step.

In groups 1 and 2, $2 \mathrm{~mL}$ of $2.5 \% \mathrm{NaOCl}$ were used before each instrument. The total volume of irrigating solution used during the chemomechanical preparations in these two groups was $14 \mathrm{~mL}$. The same volume of $\mathrm{NaOCl}$ was used during root canal instrumentation for the group 3. In all three groups, a final rinse was performed with $5 \mathrm{~mL}$ of $2.5 \% \mathrm{NaOCl}$, followed by $5 \mathrm{~mL}$ of $17 \%$ EDTA. To standardize the irrigation procedure, a peristaltic pump (VK Driller LTDA, São Paulo, Brazil) with a 30G irrigation needle (Ultradent Products Inc., South Jordan, USA) was used at a constant flow of $5 \mathrm{~mL} / \mathrm{min}$. The irrigation needle was inserted $2 \mathrm{~mm}$ short of the working length in a back-and-forth motion.

At the end of the preparation, $\mathrm{NaOCl}$ was buffered with $2 \mathrm{~mL}$ of a sterile solution of $5 \%$ sodium thiosulphate, which was placed in the root canal for 3 minutes. The root canals were filled with sterile peptone water and postoperative samples (S2) were taken in the same manner as S1. Size 20 paper cones were used to standardize the volume of solution recovered from the root canals in the initial (S1) and postoperative (S2) samples.

After postoperative sampling, the specimens were sectioned into three thirds. Then, $0.02 \mathrm{~g}$ of dentine was collected from the apical, medium, and coronal thirds of the root canal to verify the presence of 
bacterial biofilm in the root canal walls. A sterile diamond conical bur (no. 3139, Medical Burs Ind, São Paulo, Brazil) was used at $150 \mathrm{rpm}$ without irrigation. Dentine chips were collected into polypropylene tubes containing $1 \mathrm{~mL}$ of sterile peptone water. A digital precision balance (Mettler-Toledo International Inc., São Paulo, Brazil) was used to standardize the weight of dentine collected. Subsequently, 10-fold serial dilutions were performed. To quantify the microbial growth, $100 \mu \mathrm{L}$ aliquots were plated on $\mathrm{M}$-enterococcus agar in triplicates and CFU count was performed after incubation at $37^{\circ} \mathrm{C}$ for 48 hours.

Intragroup reductions in bacterial counts from S1 to S2 were assessed using Mann-Whitney U-test. Comparisons between groups were accomplished using the Kruskal-Wallis test at a significance level of $5 \%$. All analyses were performed using the SPSS 15.0 software program (SPSS Inc., Chicago, USA).

\section{Results}

Analysis of the initial bacterial count showed no significant differences between the three groups $(p=0.1222)$. All techniques were effective in reducing the mean bacteria count in the root canal lumen $(p<0.001)$. However, no significant differences were observed between the experimental groups after chemomechanical preparation in terms of the average bacterial count (log10 values) of E. faecalis in the root canal lumen (Table 1) or on the dentine chips recovered from each radicular third (Table 2). No statistically significant differences were observed among the 3 different preparation techniques in relation to the number of microorganisms remaining in dentine chips (Coronal $p=0.7077$, Medium $p=0.0781$, Apical $p=0.9607$ ).

The sterile condition of the root canal system prior to contamination with $E$. faecalis was verified, as no microbial growth was observed in the control group either.

\section{Discussion}

In the present study, the effects of different root canal preparation techniques on E. faecalis biofilm were assessed by culture method. Reciprocating instruments were found to be as effective as hand and rotary instrumentation in significantly reducing the number of microorganisms in the root canal lumen and the dentine walls. Previous ex vivo studies have shown that manual and conventional rotary preparations have similar effects on microbial populations within straight root canals..$^{14,20,21}$ This was corroborated in the present study and might be explained by the ability of the instruments to remove contaminated dentine,

Table 1. Average and standard deviation values (in $\log 10 \mathrm{CFU} / \mathrm{mL}$ ) of $E$. faecalis in the root canal lumen before and after chemomechanical preparation, and the respective percentage reduction.

\begin{tabular}{lcccc}
\hline & & Before Instrumentation (CFU/mL) & After Instrumentation (CFU/mL) & Percent Reduction \\
\hline Group & $\mathrm{n}$ & Average \pm SD & Average \pm SD & Average \pm SD \\
\hline Manual & 15 & $7.82 \pm 0.09^{\mathrm{a}}$ & $0.87 \pm 0.59^{\mathrm{b}}$ & $99.99 \pm 0.01^{\mathrm{A}}$ \\
Rotary & 15 & $7.79 \pm 0.09^{\mathrm{a}}$ & $0.79 \pm 0.58^{\mathrm{b}}$ & $99.99 \pm 0.01^{\mathrm{A}}$ \\
Reciprocating & 15 & $7.72 \pm 0.14^{\mathrm{a}}$ & $0.89 \pm 0.60^{\mathrm{b}}$ & $99.99 \pm 0.01^{\mathrm{A}}$ \\
\hline
\end{tabular}

Upper case letters $\left({ }^{A}\right.$ or $\left.{ }^{B}\right)$ indicate the presence of significant differences in percent reduction between the groups $(p<0.001)$. Lower case letters $\left({ }^{a}\right.$ or $\left.^{b}\right)$ indicate significant differences between the groups, before and after instrumentation, respectively $(p<0.001)$.

Table 2. Average and standard deviation values of (in $\log 10 \mathrm{CFU} / \mathrm{mL}$ ) of $E$. faecalis in dentine chips, according to location in the radicular third and preparation technique.

\begin{tabular}{lccc}
\hline & & Radicular Third & \\
\cline { 2 - 4 } & Coronal & Medium & Apical \\
\cline { 2 - 4 } & Average \pm SD & Average \pm SD & Average \pm SD \\
\hline Manual & $1.54 \pm 0.79^{a}$ & $1.40 \pm 0.70^{a}$ & $0.88 \pm 0.74^{\mathrm{b}}$ \\
Retary & $1.60 \pm 0.82^{\mathrm{a}}$ & $1.90 \pm 0.54^{\mathrm{a}}$ & $0.90 \pm 0.77^{\mathrm{b}}$ \\
\hline
\end{tabular}

${ }^{a}$ or ${ }^{b}$ indicate presence of significant difference among the groups $(p<0.001)$. 
thereby decreasing the amount of microorganisms in the root canal walls.

Reciprocating instrumentation is a new and promising method for the mechanical disinfection of root canals, and as with the M-Wire NiTi alloy, allows the root canal to be prepared with a single instrument. Some studies have evaluated the mechanical effectiveness of these instruments using mechanical tests, ${ }^{16,17,22,23,24}$ and have reported the great potential these new concepts have in overcoming the challenges presented during root canal manipulation, such as curvatures. ${ }^{15,22}$ However, simplification of endodontic treatment using only one instrument raises concerns about its effectiveness in promoting proper disinfection of the root canal system.

According to Ricucci and Siqueira $\mathrm{Jr}^{25}$ most cases of periradicular infections are caused by intraradicular bacterial biofilms. They found biofilm structures in $80 \%$ and $74 \%$ cases of primary and secondary infections, respectively. In the present work, a biofilm was formed after 28 days of constant contamination of a root canal in order to simulate clinical conditions. This period has been shown to be sufficient to promote $E$. faecalis biofilm formation inside root canals. ${ }^{11}$ In the negative control group, there was no specimen contamination at any time, whereas the root canals in the postoperative samples (S1) showed a high bacterial count, confirming the validity of the method.

A microbiological culture method was employed to assess the presence of viable microorganisms, which were sampled from the root canal lumen before and after chemomechanical preparation, using sterile paper points. Microbial populations were reduced by more than $99 \%$ with all 3 preparation techniques. These results are in agreement with previous studies using similar methodologies..$^{14,26}$

Unlike previous studies, which assessed the effectiveness of the reciprocating technique in disinfecting root canals, the present study involved sectioning of the roots into thirds, and collection of dentin chips from the root canal walls. This approach enables the evaluation of the effects of the different preparation techniques on different portions of the root canal. E. faecalis is able to form biofilms and enter the dentinal tubules. Low-speed diamond burs were used to collect microorganisms in the biofilm adhering to the dentinal walls and inside the dentinal tubules. Consistent with the results reported by Câmara et al. ${ }^{10}$ analysis of the dentine chips in the present study revealed the presence of microorganisms in the root canal system in all three groups.

Although chemomechanical preparation with the Reciproc system involved the use of a single file only, the results obtained were not significantly different from those achieved with other tested techniques. This may be attributed to the final volume of the root canal after chemomechanical preparation. Apical enlargement was performed until a diameter of $0.5 \mathrm{~mm}$ was reached in all three groups. Thus, the amount of dentine removed, especially in the middle and apical thirds, is similar for any of the studied techniques. ${ }^{27}$ Paqué et al. ${ }^{5}$ reported that only $20.1 \%$ to $40.4 \%$ of the total volume of oval-shaped root canal is treated during chemomechanical preparation with hand or rotary instruments. Thus, untreated surfaces are disinfected mainly by the action of the irrigating solutions, which may explain the absence of significant differences between the three groups in the present study. Dynamic irrigation with antimicrobial substances, such as sodium hypochlorite, may play an important role during endodontic treatment.

Analysis of the radicular thirds revealed higher CFU counts in the cervical third, followed by the middle and apical thirds. These results, which are similar to those from previous studies, were mainly due to the greater number of dentinal tubules in the corresponding portions of the root canal system. ${ }^{14,26}$ CFU counts were low in the apical third after chemomechanical preparation; perhaps because all the root canals were enlarged to file size 50 , as the initial diameter of the canals were standardized using size $30 \mathrm{~K}$-type files. This standardization was chosen based on previous studies, ${ }^{28,29}$ which showed that the average diameter of the root canal $1.0 \mathrm{~mm}$ away from the apical foramen may range from 0.28 to $0.45 \mathrm{~mm}$. According to Hecker et al.,$^{30}$ in order to achieve proper debridement of this portion of the root canal, the preparation should be carried out using instruments starting from size 40 until size 70 , which might increase the efficacy of irrigation and promote better disinfection. 
A critical factor to be considered is the limitation of the culture method itself because only viable and cultivable microorganisms could be counted. Additionally, some strains of E. faecalis can enter a stationary phase, making them undetectable with conventional culture methods. Thus, the data obtained from the bacterial count must be interpreted with caution. To date, sterilization of infected root canal systems cannot be achieved in vivo by any known instrumentation technique or irrigation protocol. Also, the minimum bacterial load remaining inside the root canal, necessary to promote the healing of periapical tissues or for the maintenance of their health, is still unknown. Therefore, additional clinical trials should be conducted to evaluate the effects of different instrumentation techniques and irrigation protocols on the outcome of the endodontic treatment. Based on the results in the present study, clinicians

\section{References}

1. Rôças IN, Siqueira Jr JF. Identification of bacteria enduring endodontic treatment procedures by a combined reverse transcriptase-polymerase chain reaction and reverse-capture checkerboard approach. J Endod. 2010 Jan;36(1):45-52.

2. Ricucci D, Siqueira Jr JF. Anatomic and microbiologic challenges to achieving success with endodontic treatment: a case report. J Endod. 2008 Oct;34(10):1249-54.

3. Siqueira Jr JF, Lima KC, Magalhães FAC, Lopes HP, Uzeda $\mathrm{M}$. Mechanical reduction of the bacterial population in the root canal by three instrumentation techniques. J Endod. 1999 May;25(5):332-5.

4. Siqueira Jr JF, Alves FR, Almeida BM, Oliveira JCM, Rôças IN. Ability of chemomechanical preparation with either rotary instruments or self-adjusting file to disinfect oval-shaped root canals. J Endod. 2010 Nov;36(11):1860-5.

5. Paqué F, Balmer M, Attin T, Peters OA. Preparation of ovalshaped root canals in mandibular molars using nickel-titanium rotary instruments: a micro-computed tomography study. J Endod. 2010 Apr;36(4):703-7.

6. Alves FRF, Rôças IN, Almeida BM, Neves MAS, Zoffoli J, Siqueira Jr JF. Quantitative molecular and culture analyses of bacterial elimination in oval-shaped root canals by a single-file instrumentation technique. Int Endod J. 2012 Sep;45(9):871-7.

7. Stuart CH, Schwartz SA, Beeson TJ, Owatz C. Enterococcus faecalis: its role in root canal treatment failure and current concepts in retreatment. J Endod. 2006 Feb;32(2):93-8. should choose the instrument type that they are more confident with, and no matter which technique they opt to use, it must be performed in association with abundant irrigation.

\section{Conclusion}

There were no differences among manual, rotary, and reciprocating instrumentation techniques in terms of their ability to disinfect oval-shaped root canals. Reciprocating instrumentation in association with $2.5 \% \mathrm{NaOCl}$ was as effective as manual and rotary techniques in reducing the number of microorganisms within the oval root canals.

\section{Acknowledgements}

We thank the Conselho Nacional de Desenvolvimento Cientifico e Tecnológico (CNPq) for the support on this project (process 140457/2011-9).

8. George S, Kishen A, Song KP. The role of environmental changes on monospecies biofilm formation on root canal wall by Enterococcus faecalis. J Endod. 2005 Dec;31(12):867-72.

9. Chivatxaranukul P, Dashper SG, Messer HH. Dentinal tubule invasion and adherence by Enterococcus faecalis. Int Endod J. 2008 Oct; $41(10): 873-82$.

10. Câmara AC, Albuquerque MM, Aguiar CM, Correia ACB. In vitro antimicrobial activity of $0.5 \%, 1 \%$, and $2.5 \%$ sodium hypochlorite in root canals instrumented with the ProTaper Universal system. Oral Surg Oral Med Oral Pathol Oral Radiol Endod. 2009 Aug;108(2):55-61.

11. Soares JA, Carvalho MAR, Santos SMC, Mendonça RM, Ribeiro-Sobrinho AP, Brito-Junior M, et al. Effectiveness of chemomechanical preparation with alternating use of sodium hypochlorite and EDTA in eliminating intracanal Enterococcus faecalis biofilm. J Endod. 2010 May;36(5):894-8.

12. Alves FRF, Almeida BM, Neves MAS, Rôças IN, Siqueira Jr JF. Time-dependent antibacterial effects of the self-adjusting file used with two sodium hypochlorite concentrations. J Endod. 2011 Oct;37(10):1451-5.

13. Machado ME, Nabeshima CK, Leonardo MF, Reis FA, Britto $\mathrm{ML}$, Cai S. Influence of reciprocating single-file and rotary instrumentation on bacterial reduction on infected root canals. Int Endod J. 2013 Nov;46(11):1083-7.

14. Nakamura VC, Cai S, Candeiro GTM, Ferrari PH, Caldeira $\mathrm{CL}$, Gavini G. Ex vivo evaluation of the effects of several root canal preparation techniques and irrigation regimens on a mixed microbial infection. Int Endod J. 2013 Mar;46(3):217-24. 
15. Yared G. Canal preparation using only one Ni-Ti rotary instrument: preliminary observations. Int Endod J. 2008 Apr;41(4):339-44.

16. Varela-Patiño $P$, Ibañez-Párraga A, Rivas-Mundiña B, Cantatore G, Otero XL, Martin-Biedma B. Alternating versus continuous rotation: a comparative study of the effect on instrument life. J Endod. 2010 Jan;36(1):157-9.

17. Gavini G, Caldeira CL, Akisue E, Candeiro GT, Kawakami DA. Resistance to flexural fatigue of Reciproc R25 files under continuous rotation and reciprocating movement. J Endod. 2012 May;38(5):684-7.

18. Alapati SB, Brantley WA, Iijima M, Clark WAT, Kovarik L, Buie C, et al. Metallurgical characterization of a new nickeltitanium wire for rotary endodontic instruments. J Endod. 2009 Nov;35(11):1589-93.

19. Yahata Y, Yoneyama T, Hayashi Y, Ebihara A, Doi H, Hanawa $\mathrm{T}$, et al. Effect of heat treatment on transformation temperatures and bending properties of nickel-titanium endodontic instruments. Int Endod J. 2009 Jul;42(7):621-6.

20. Berber VB, Gomes BP, Sena NT, Vianna ME, Ferraz CC, Zaia AA, et al. Efficacy of various concentrations of $\mathrm{NaOCl}$ and instrumentation techniques in reducing Enterococcus faecalis within root canals and dentinal tubules. Int Endod J. 2006 Jan;39(1):10-7.

21. Dalton BC, Orstavik D, Phillips C, Pettiette M, Trope M. Bacterial reduction with nickel-titanium rotary instrumentation. J Endod. 1998 Nov;24(11):763-7.

22. De-Deus G, Moreira EJL, Lopes HP, Elias CN. Extended cyclic fatigue life of F2 ProTaper instrument used in reciprocating movement. Int Endod J. 2010 Dec;43(12):1063-8.
23. Gao Y, Shotton V, Wilkinson K, Phillips G, Johnson WB. Effects of raw material and rotational speed on the cyclic fatigue of ProFile Vortex rotary instruments. J Endod. 2010 Jul;36(7):1205-9.

24. Shen Y, Qian W, Abtin H, Gao Y, Haapasalo M. Fatigue testing of controlled memory wire nickel-titanium rotary instruments. J Endod. 2011 Jul;37(7):997-1001.

25. Ricucci D, Siqueira Jr JF. Biofilms and apical periodontitis: study of prevalence and association with clinical and histopathologic findings. J Endod. 2010 Aug;36(8):1277-88.

26. Souza EB, Cai S, Simionato MR, Lage-Marques JL. Highpower diode laser in the disinfection in depth of the root canal dentin. Oral Surg Oral Med Oral Pathol Oral Radiol Endod. 2008 Jul;106(1):68-72.

27. Gergi R, Osta N, Bourbouze G, Zgheib C, Arbab-Chirani R, Naaman A. Effects of three nickel titanium instrument systems on root canal geometry assessed by micro-computed tomography. Int Endod J. 2014 Apr 9. [Epub ahead of print].

28. Wu MK, Barkis D, Roris A, Wesselink PR. Does the first file to bind correspond to the diameter of the canal in the apical region?. Int Endod J. 2002 Mar;35(3):264-7.

29. Grande NM, Plotino G, Pecci R, Bedini R, Pameijer $\mathrm{CH}$, Somma F. Micro-computerized tomographic analysis of radicular and canal morphology of premolars with long oval canals. Oral Surg Oral Med Oral Pathol Oral Radiol Endod. 2008 Sep;106(3):70-6.

30. Hecker H, Bartha T, Löst C, Weiger R. Determining the apical preparation size in premolars: part III. Oral Surg Oral Med Oral Pathol Oral Radiol Endod. 2010 Jul;110(1):118-24. 